Sharif University of Technology
Scientia Iranica
SCIENTIA
I RAN ICA
http://scientiairanica.sharif.edu

\title{
Centrifuge modelling of monopiles subjected to lateral loading
}

\author{
S. Darvishi Alamouti, M. Moradi*, and M.R. Bahaari \\ School of Civil Engineering, College of Engineering, University of Tehran, Tehran, Iran.
}

Received 5 February 2017; received in revised form 11 October 2017; accepted 5 March 2018

KEYWORDS
Monopile;
Lateral loading;
Short pile;
Centrifuge modelling;
p-y curve;
Secant stiffness.

\section{Introduction}

Piled foundations are frequently used in marine structures to resist the lateral cyclic loading produced by wind, waves, or ship berthing. A monopile is a single pile with a small aspect ratio (length over diameter), which rotates in rigid form instead of bends when subjected to lateral loads $[1,2]$. The current Offshore Wind Turbine (OWT) design practice uses the Winkler approach for analysis of monopile foundations. In this method, the pile is modelled as a beam on a set of

\footnotetext{
*. Corresponding author. Tel.: +982188909468;

Fax: +982188911070

E-mail addresses: saeed_darvishi@ut.ac.ir (S. Darvishi

Alamouti); mmoradi@ut.ac.ir (M. Moradi);

mbahari@ut.ac.ir (M.R.Bahaari)
}

doi: $10.24200 /$ sci. 2018.20222 nonlinear uncoupled springs as p-y curves representing soil-pile interaction [3-6].

The main shortcoming of the current methodology is that the p-y curves are based on empirical testing on the long slender piles, which are adopted and implemented in offshore oil and gas standards [1]. However, some differences exist between wind turbine foundations and those of offshore platforms. The high ratio of horizontal to vertical loading and small aspect ratio of the piles in OWTs are the major differences. Moreover, knowledge and prediction of longterm performance of foundations in terms of stiffness and deformation are very important in OWT monopile structures. Short-term data on the existing structures in the early years of operation have shown that the fundamental frequency of the structures $\left(f_{0}\right)$ has been under-predicted at the design stage [7].

Cyclic lateral loading affects pile behaviour in two ways; accumulation of rotation and changes in secant 
stiffness $[1,8]$. Recent studies have shown that the effect of cyclic loading on a pile strongly depends on the load characteristics and number of cycles, e.g. [1,912]. Several studies have investigated accumulated displacement and changes in stiffness of monopiles under cyclic loading. Long and Vanneste (1994) [9] and Lin and Liao (1999) [10] reviewed earlier studies and proposed a new method based on field tests to reduce soil resistance using power law as a function of the number of cycles. Several authors have proposed approaches to determining the effect of cyclic loading based on different theories. Triaxial tests with theoretical and numerical models were employed by Lesny and Hinz (2007) [13] and Achmus et al. (2009) [14]. Rosquoët et al. (2007) [11] investigated the change in tangent stiffness and accumulation of displacement under lateral cyclic loading on a scaled monopile in an $\eta g$ model. They observed that accumulation of displacement followed a logarithmic trend.

Leblanc et al. (2010) [1] introduced new parameters to identify the load characteristics of magnitude and direction. Their accumulation model obeyed power law as proposed by Long and Vanneste (1994) [9] and Lin and Liao (1999) [10]. Klinkvort et al. (2010) [15] performed six lateral cyclic centrifuge tests on laterallyloaded piles in dense and dry sand. They observed that cyclic loading increased the secant stiffness and they estimated accumulated cyclic displacement. Rudolph et al. (2014) [16] considered the effect of load directionality on the cyclic behaviour of monopiles and concluded that a change in loading direction significantly increased accumulation of displacement over the unidirectional loading. Although much significant work has been done in recent years, the lack of comprehensive data to create general rules about the cyclic behaviour of monopoles is a major problem. For instance, Leblanc et al. (2010) [1] reported only increases in monopile secant stiffness in sandy soil, whereas Klinkvort and Hededal (2013) [12] also observed decreases under specific loading patterns.

General design rules have not yet been established or adopted in design codes considering soilpile interaction issues, specifically for short monopiles. To this aim, it is required to build a comprehensive database which includes different soil and pile information. This database should encompass many different conditions including different soil types and properties (e.g. different relative densities for sand), different pile geometries (diameter, length, eccentricity, aspect ratio), and different loading patterns in cyclic behaviour. Further laboratory investigations are needed to extend the application of the experimental data generated and add to the existing database on monotonic and cyclic behaviours of monopiles. In addition, because of different observations reported for laterally loaded rigid monopiles, it is still needed to improve the knowledge of this subject. This paper presents a series of displacement-controlled centrifuge tests to investigate the lateral behaviour of a short monopile in sand with approximate relative density of $60 \%$, which is considered as an average value for medium-dense sand. The data collected gives good information about the monotonic and cyclic responses of monopiles and provides further insights into the monopile load-displacement and stiffness behaviour.

\section{Methodology}

\subsection{Centrifuge modelling, scaling law, and dimensional analysis}

In soil, especially in sand, stress-strain-strength behaviour depends on the effective stress. It is expected that in a geotechnical centrifuge, the in situ level of stress can reproduce approximately the same stressstrain behaviour as is found in the field [17]. Therefore, equivalence between model and prototype stress levels and stress-strain-strength behaviours establishes similitude laws. Table 1 shows correlation between model and prototype parameters at generated centrifugal acceleration of $\eta g$.

In all physical modelling, it is important to perform dimensional analysis on all independent governing parameters of the modelled phenomenon. Dimensional analysis leads to a set of non-dimensional ratios of governing parameters in order to transform model results into prototype scale. For this purpose, nondimensional ratios should be identical between model and prototype to avoid scale effects. On the subject of the present study, a dimensional analysis has been performed by Klinkvort et al. (2013) [18]. Following is the results of their analysis:

$$
\frac{H}{\gamma^{\prime} D^{3}}=f\left(\frac{y}{D}, \frac{L}{D}, \frac{e}{D}, \frac{E_{P} I_{P}}{E_{S} D^{4}}, \phi^{\prime}, \frac{R_{a}}{d_{50}}, \frac{D}{d_{50}}\right),
$$

where $H$ is applied load, $D$ is pile diameter, $y$ is pile lateral displacement, $e$ is load eccentricity, $R_{a}$ is pile average roughness, and $d_{50}$ is soil average grain size.

Table 1. Scaling law in centrifuge modelling.

\begin{tabular}{lc}
\hline \multicolumn{1}{c}{ Parameters } & Scaling law \\
\hline Density & 1 \\
Length & $1 / \eta^{\mathrm{a}}$ \\
Displacement & $1 / \eta$ \\
Strain & 1 \\
Stress & 1 \\
Force & $1 / \eta^{2}$ \\
Bending stiffness & $1 / \eta^{4}$ \\
Acceleration & $\eta$ \\
\hline
\end{tabular}

${ }^{a} \eta$ is scaling factor. 
Table 2. Test program (in model scale).

\begin{tabular}{cccccc}
\hline Test ID & Type & No. of cycles & $\boldsymbol{y}_{\max }^{\mathbf{a}}(\mathbf{m m})$ & $\boldsymbol{y}_{\mathbf{m i n}}(\mathbf{m m})$ & Rate of app. disp. \\
\hline TM1 & Monotonic & - & 35 & 0 & $0.1 \mathrm{~mm} / \mathrm{s}$ \\
TC1 & Cyclic & 130 & 12 & -5.8 & $0.1 \mathrm{~Hz}$ \\
TC2 & Cyclic & 100 & 4 & -2 & $0.1 \mathrm{~Hz}$ \\
TC3 & Cyclic & 110 & 4 & 0 & $0.1 \mathrm{~Hz}$ \\
TC4 & Cyclic & 120 & 4 & -4 & $0.1 \mathrm{~Hz}$ \\
TC5 & Cyclic & 100 & 4.5 & 1.5 & $0.1 \mathrm{~Hz}$ \\
TC6 & Cyclic & 100 & 3 & -2 & $0.1 \mathrm{~Hz}$ \\
TC7 & Cyclic & 100 & 5 & -3 & $0.1 \mathrm{~Hz}$ \\
\hline
\end{tabular}

a $y$ : applied displacement.

Other parameters are well known. Thanks to centrifuge technology, all these ratios are identical across the scale, except the last one. This ratio should be kept large enough to avoid scale problems.

The centrifuge tests designed in the present work sought to determine the cyclic behaviour of a stiff monopile under lateral loading. The program for the tests consisted of one monotonic and seven cyclic loading experiments at $40 \mathrm{~g}$ (Table 2). Note that all tests were carried out under displacement-controlled loading. All tests were performed by Actidyn C672 centrifuge at University of Tehran. The centrifuge beam (radius $3.5 \mathrm{~m}$ ) was equipped with a pendulum swinging platform that would accommodate a model up to $1 \mathrm{~m} \times 0.8 \mathrm{~m} \times 0.8 \mathrm{~m}$ and could accelerate a onetone package to $130 \mathrm{~g}$. The centrifuge was controlled by a state-of-the-art computer management system. The platform radius was $3.0 \mathrm{~m}$ and the nominal radius was $2.7 \mathrm{~m}$. Further information about the centrifuge facility can be found in [19].

\subsection{Properties and preparation of the sand sample}

A rectangular strongbox $80 \mathrm{~cm} \times 60 \mathrm{~cm} \times 50 \mathrm{~cm}$ in size was used to prepare the soil sample. Firoozkuh161 standard sand with an approximate relative density of $60 \%$ was used. This sand is used as the standard in geotechnical testing in Iran and several research papers can be found dealing with the behaviour of this sand in different states. The sand is produced by crushing of parent rocks from Firoozkuh mine in the north-east of Tehran. It mainly consists in fine- and medium-sized golden subangular particles. Further information regarding the sand properties and mechanical behaviour can be found in Farahmand et al. (2016) [20]. Table 3 compares properties of the sand with other standard types found in the literature.

For preparation of soil samples, soil weightvolume relationships were used. Strongbox walls were divided into $2.5 \mathrm{~cm}$ layers for soil compaction. Therefore, having volume of each layer of the sand, moisture
Table 3. Sand properties compared to other standard soils.

\begin{tabular}{lccccc}
\hline \multicolumn{1}{c}{ Sand type } & $\boldsymbol{d}_{\mathbf{5 0}}(\mathbf{m m})$ & $\boldsymbol{C}_{\boldsymbol{u}}^{\mathrm{a}}$ & $\boldsymbol{e}_{\min }$ & $\boldsymbol{e}_{\max }$ & $\boldsymbol{G}_{\boldsymbol{s}}$ \\
\hline Firoozkuh 161 & 0.30 & 1.87 & 0.574 & 0.874 & 2.658 \\
Fontainebleau & 0.17 & 1.60 & 0.548 & 0.859 & 2.646 \\
Toyoura & 0.18 & 1.54 & 0.597 & 0.977 & 2.650 \\
\hline
\end{tabular}

${ }^{\mathrm{a}} C_{u}$ : Coefficient of uniformity.

content ( $5 \%$ was used to facilitate compacting), relative density, and thereby specific weight, it was easy to calculate weight of the required soil for compaction in each layer. The sand was poured almost evenly distributed in the box. After pouring, it was compacted using a manual compactor until the compacted soil fitted the specified layer of the box. In this method, the relative density was not expected to be exact; however, approximate relative density of $60 \%$ was achieved with acceptable accuracy.

The scaling of the ratio of grain size to pile diameter is difficult to achieve [17], because a model uses the same soil as that used in the prototype, meaning that the grain size to pile diameter ratio in the model is $n$ times larger than the actual size. Mühlhaus and Vardoulakis [21] showed that progressive failure in small model tests with the material same as that in the prototype was questionable. The ratio of particle size $\left(d_{50}\right)$ to structure size $(B)$ should be sufficiently small to overcome this drawback. Ovesen (1979) [22] showed that for a vertical loaded plate, scale effect could be neglected if $B / D_{n 50}>30$. If $D_{n 50}=0.3 \mathrm{~mm}$ and $B=50 \mathrm{~mm}$, the ratio would be greater than 166 and the scale effect would have a negligible effect on the results of the present experiments.

\subsection{Modelled pile}

The model pile was a circular stainless steel pile with an outer diameter of $5 \mathrm{~cm}$ and thickness of $1.25 \mathrm{~mm}$. At $40 \mathrm{~g}$ of acceleration, the pile at prototype scale should be $2 \mathrm{~m}$ in diameter and $5 \mathrm{~cm}$ in thickness in dry sand. Summary of structural properties of the modelled pile is shown in Table 4 in model scale. 
Table 4. Model pile properties.

\begin{tabular}{lcc}
\hline \multicolumn{1}{c}{ Property } & Value in model scale & Unit \\
\hline Pile diameter & 50 & $\mathrm{~mm}$ \\
Wall thickness & 1.25 & $\mathrm{~mm}$ \\
Embedded length & 250 & $\mathrm{~mm}$ \\
Load eccentricity & 350 & $\mathrm{~mm}$ \\
Total length & 750 & $\mathrm{~mm}$ \\
Young's modulus & 207 & $\mathrm{GPa}$ \\
EI & $11.78 \times 10^{9}$ & $\mathrm{~N} . \mathrm{mm}^{2}$ \\
Weight & 11.2 & $\mathrm{~N}$ \\
\hline
\end{tabular}

Half-bridge strain gauges were attached to the pile at the six stations at distances of $6.5,12,17.2$, $21.7,27.3$, and $32.5 \mathrm{~cm}$ from the pile bottom. The pile bending moments were calculated at different depths for moment calibration against voltage. Figure 1 presents a schematic sketch of the test setup. In all tests, embedded length and load eccentricity were kept constant at $25 \mathrm{~cm}(5 \mathrm{D})$ and $35 \mathrm{~cm}(7 \mathrm{D})$, respectively.

\subsection{Instrumentation}

In all tests, cyclic displacements applied by the loading shaft were measured using a Linearly Variable Differential Transformer (LVDT). Another LVDT was placed $15 \mathrm{~cm}$ beneath the loading point. This extra LVDT would help to measure pile deflections at the soil surface. The magnitude of the lateral load caused by the applied displacement was measured using a load cell. The load cell non-linearity and non-repeatability were $\leq 0.03 \%$ R.O. and $\leq 0.02 \%$ R.O., respectively (R.O. denotes rated output). Testing and pile movements were filmed by a set of cameras for monitoring the test procedure. Agilent E1422 data acquisition system installed in the centrifuge was used to collect and store output data. Sampling rate was $0.01 \mathrm{~s}$ for monotonic and $0.05 \mathrm{~s}$ for cyclic tests. Low-pass Butterworth filtering type was used for data processing.

All the measurement devices were calibrated several times during the work to ensure their linear response. Load cell was calibrated using different known weights applied and measuring output voltages. Similar method was used for LVDTs with known displacement. For calibration of strain gauges of the pile, the pile was placed on two simple supports and different weights were applied to the middle of the beam. Then, the calculated moments at the half-bridge stations were calibrated against voltages.

\subsection{Loading and tests procedure}

Before cyclic testing, a monotonic loading test was performed to make an approximation of the monopile loadbearing capacity. Recent studies $[1,12]$ have reported the effect of load characteristics and the number of load cycles on monopile cyclic behaviour. They define two non-dimensional parameters as follows:

$$
\begin{aligned}
\xi_{b} & =\frac{\text { Maximum Load }}{\text { Ultimate Capacity }}, \\
\xi_{c} & =\frac{\text { Minimum Load }}{\text { Maximum Load }}
\end{aligned}
$$

The load used in this definition applies to either

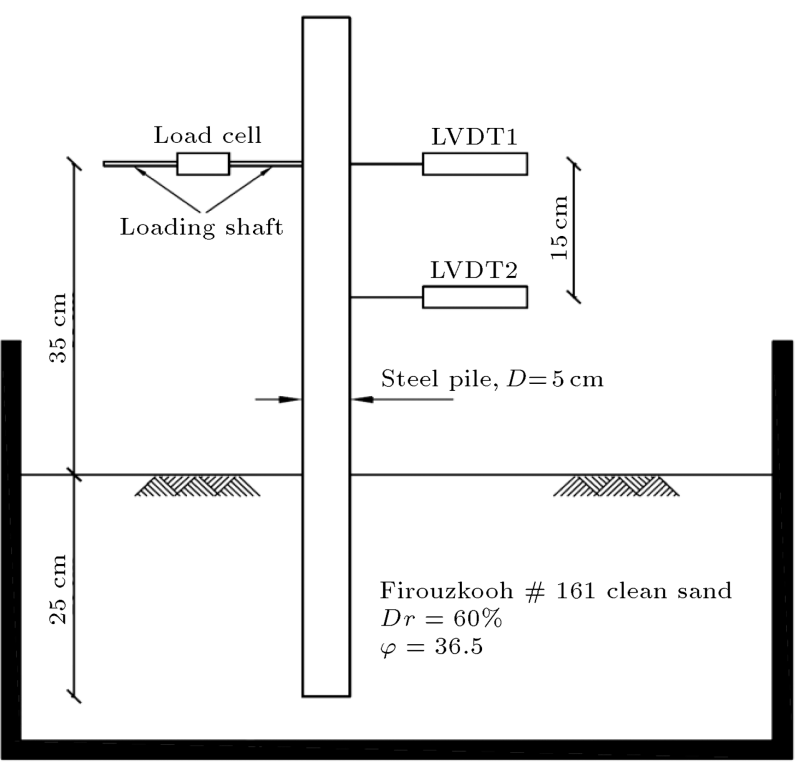

(a)

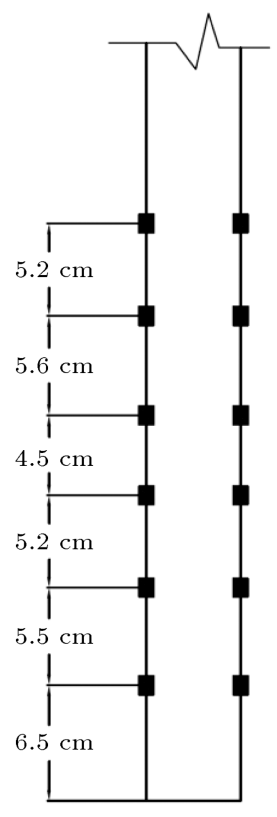

(b)

Figure 1. (a) Schematic sketch of test setup. (b) Strain gauge locations. 
horizontal force, bending moment, or any parameter representing lateral demand on the pile.

Note that in an actual offshore environment, the load level is not constant and varies from cycle to cycle. In the cyclic tests, except TC1, the load levels were chosen to reflect the fatigue limit state. The primary cyclic loads causing high cycle fatigue in OWTs are about one-third the ultimate capacity of the pile [1].

A new stepper motor was programmed to generate controlled displacement. The rotation of the stepper shaft was transferred to a ball screw by means of a toothed belt. The ball screw transformed rotation to translation and the translational movement was conveyed to a loading shaft, which displaced the monopile. Figure 2 shows the main components and assembly of the loading device. The stepper motor was able to create displacement in ramp, stair, triangular, and sinusoidal patterns. A combination of ramp and sinusoidal patterns was used. Only the ramp pattern was used to change the cyclic ratio at the beginning of loading. It is noted that the accuracy of the stepper motor was 2000 pulse/round and a calibration coefficient of 0.365 was used to convert round to $\mathrm{mm}$ of displacement. Complete setup of the present work can be seen in Figure 3.

For each test, the soil sample was newly prepared as discussed previously in Section 2.2. Then, loading frame was installed on the strongbox and the position

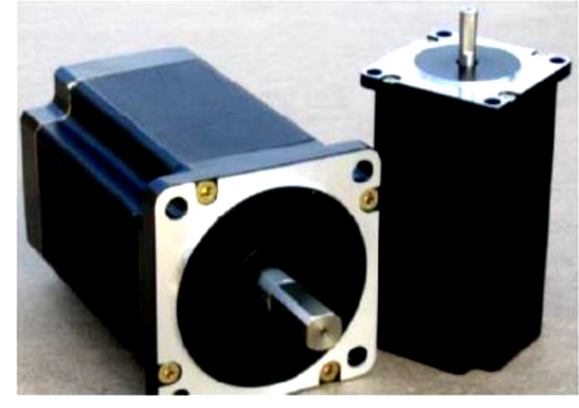

(a)

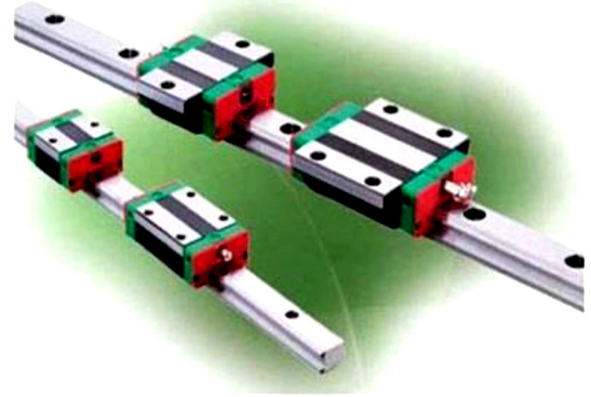

(c)

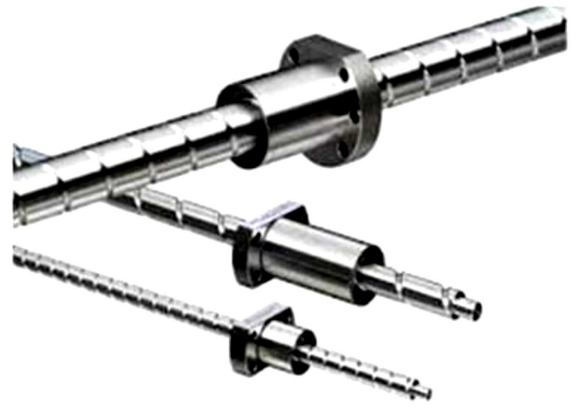

(b)

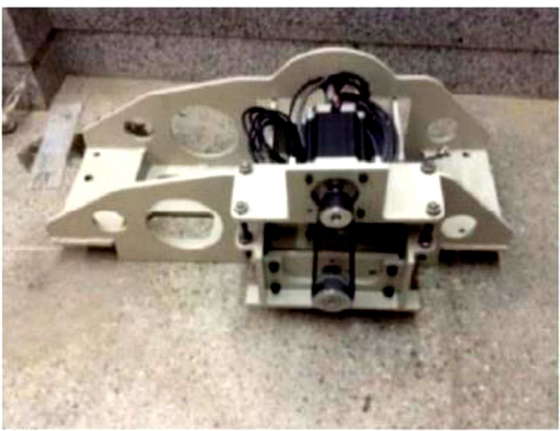

(d)

Figure 2. Loading device: (a) Stepper motor, (b) ball screw, (c) wagon, and (d) device assembly.
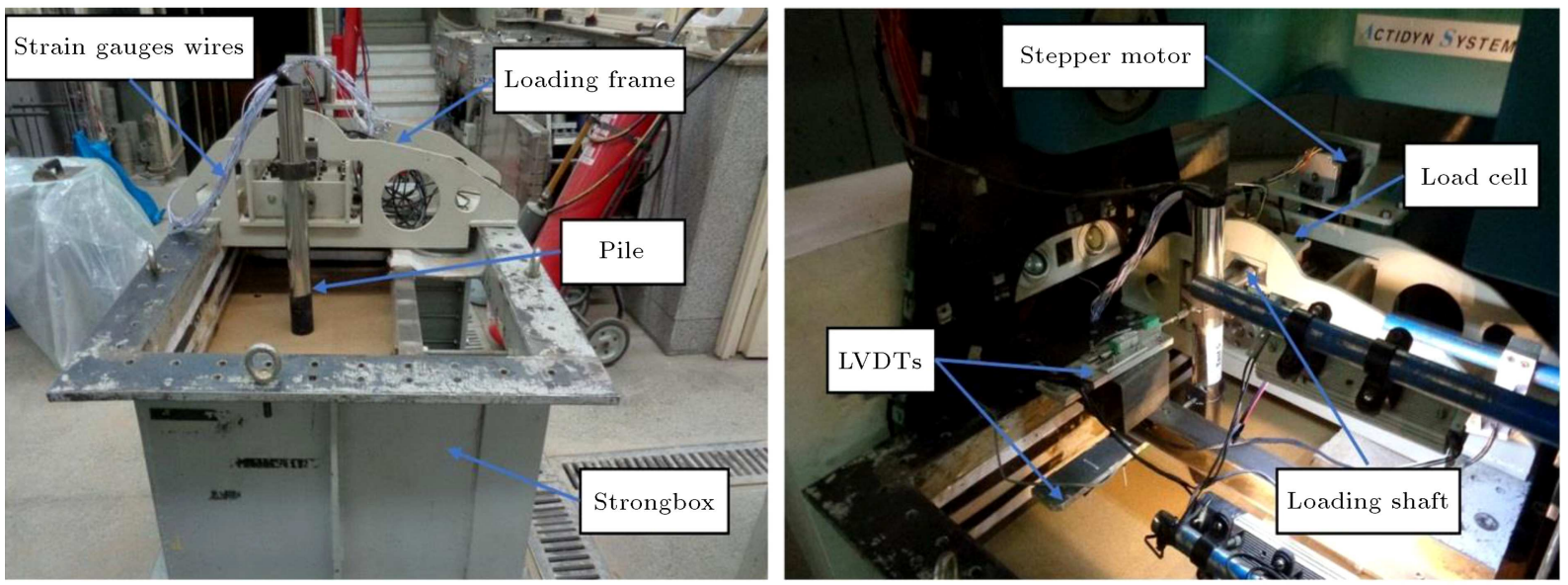

Figure 3. Complete test setup and instrumentation. 
of the loading shaft was adjusted. Afterwards, the pile was driven gradually into the soil by a hammer vertically until the desired penetration was achieved. After pile installation, loading shaft was attached to the pile with a hinged round clamp. The prepared heavy model was moved to the machine basket with a small crane. Before spinning the basket, all cables coming from strain gauges, LVDTs, and loadcell were connected to data logger channels. Also, stepper motor was triggered by attaching its wires to a power supply and command drive. Then, the centrifuge was accelerated up to $40 \mathrm{~g}$ and finally, displacements were applied to the pile.

\subsection{Dry versus saturated sand}

All tests were carried out under dry conditions. The moisture content of $5 \%$ was used to facilitate compacting; this value was not expected to affect the test results based on previous experiences in the physical modeling and centrifuge laboratory testing on wet and dry sand. As the study mainly deals with offshore wind turbines with their monopile foundations installed in saturated soils, scaling factor for equivalent saturated condition is also introduced. The procedure proposed by Lie et al. (2010) [8] was used to scale the test results under saturated conditions. In this procedure, it was assumed that no pore pressure was generated during loading and effective stress under saturated conditions would be equivalent to that under dry conditions after adjusting the geometrical scaling factor. In other words, the increase in gravitational acceleration was not equal to the geometrical scaling factor. This approach was validated by Klinkvort and Hededal (2014) [23], who conducted a series of identical tests on dry and saturated sand and compared the results. By defining geometrical scaling factor, $N_{s}$, and the increase in gravitational acceleration, $\eta$, the prototype parameters under saturated conditions would correlate with the model parameters under dry conditions using the new geometrical scaling factor as follows:

$$
N_{s}=\frac{\gamma_{\text {dry }}^{\prime}}{\gamma_{\text {sat }}^{\prime}} \times \eta .
$$

It should be noted that, accordingly, the tests are only valid for completely drained conditions.

\subsection{Limited number of cycles}

During the lifetime of an offshore structure, about $10^{7}$ load cycles are expected from environmental loading. These cycles can vary one by one in magnitude, direction, cycling, and frequency; however, an actual offshore environment cannot be simulated in the lab. Testing for cycle numbers is time-consuming and expensive, especially in centrifuge modelling. It is usual to carry out tests with a limited number of cycles and then, extrapolate the results for the target numbers.
Note that the trend of results based on a limited number of cycles can change after covering a larger number of cycles [16] and this requires examination in future studies. In the present study, limitations required that the number of cycles be limited to 130 .

\subsection{Limitations of test setup and experiments} In physical modelling investigations, exact prototype condition is almost impossible to replicate and some approximations have to be accepted [17]. Limited space of the centrifuge basket is a restriction on the model size. This imposes limitation on the strongbox dimensions and consequently, further limitations on the monopile geometry including diameter, embedment, and load eccentricity. In real offshore wind turbines, the applied load eccentricity is considerably high; therefore, we decided to take $1 D$ clearance below pile tip $[24,25]$ to have maximum load eccentricity. Except pile self-weight, there was no additional counter weight or vertical load on the pile. Therefore, considering purely lateral behaviour and small vertical stresses beneath the pile, it was expected that the pile response would not be influenced by the bottom boundary [25]. The pile was installed at $1 \mathrm{~g}$ by driving with a hammer weighing $1.455 \mathrm{~kg}$. Installation at $1 \mathrm{~g}$ would not reproduce prototype stress condition around pile; nevertheless, this difference would not affect the pile lateral response, significantly [26]. Box boundaries might affect pile response. Liu et al. (2011) [27] showed that the soil zone at most $6 \sim 9$ times the pile diameter would be deformed in loading direction. Considering box length $(80 \mathrm{~cm})$ and the pile diameter $(5 \mathrm{~cm})$, at least the distance of $6 D(30 \mathrm{~cm})$ between outer face of the pile and inner face of the box was kept in all tests to minimize boundary effects. Another drawback of centrifuge modelling is non-uniform field of acceleration in the whole model. This is because the inertial acceleration $\left(r \omega^{2}\right)$ is proportional to radius of rotation $(r)$, which varies throughout the model. The error coming from this limitation will be negligible (less than $3 \%$ ) if the ratio of model depth $\left(h_{m}\right)$ to effective rotational $\operatorname{arm}\left(R_{e}\right)$ is less than 0.2 [17]. In the present study, $R_{e}$ is $2.7 \mathrm{~m}$ and $h_{m}$ is $0.3 \mathrm{~m}$, giving $h_{m} / R_{e}=0.11$; therefore, error of vibrational $g$-level is negligible.

\section{Results and discussion}

The results of the test are presented in prototype scale. To facilitate comparison between the results regardless of dry or saturated condition of the sand, normalized parameters are used as listed in Table 5. Here, the pile diameter, $D$, and sand effective density, $\gamma^{\prime}$, are chosen for normalization.

\subsection{Monotonic test}

Monotonic testing was performed at a constant loading 
Table 5. Non-dimensional parameters.

\begin{tabular}{lc}
\hline Horizontal force $(\tilde{H})$ & $\frac{H}{\gamma^{\prime} D^{3}}$ \\
Bending moment $(\tilde{M})$ & $\frac{M}{\gamma^{\prime} D^{4}}$ \\
Displacement & $\frac{y}{D}$ \\
Aspect ratio & $\frac{L}{D}$ \\
Load eccentricity & $\frac{e}{D}$ \\
\hline
\end{tabular}

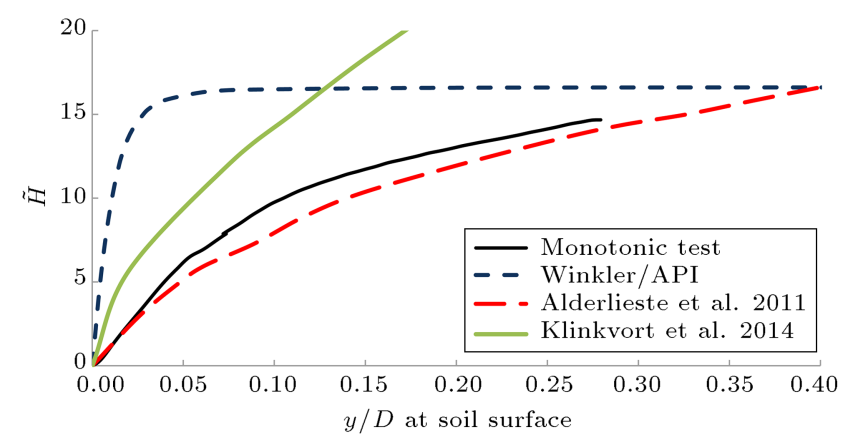

Figure 4. Monotonic test results in comparison with API/springs Winkler model, Alderlieste et al. (2011) [25], and Klinkvort and Hededal (2014) [23].

rate of $0.1 \mathrm{~mm} / \mathrm{s}$ to ensure drained conditions (pseudostatic). The results of monotonic testing on normalized pile deflection at the soil surface are shown in Figure 4. Results are compared with two similar experimental studies as well as an equivalent Winkler model; their specifications are shown in Table 6. In Winkler model, soil was modelled using $\mathrm{p}-\mathrm{y}$ curves recommended by API code [28]. These curves relate soil reaction $p$ to pile local horizontal displacement $y$ in different depths via the following equation:

$$
p=A P_{u} \tanh \left(\frac{K z y}{A P_{u}}\right),
$$

where $K$ is initial modulus of subgrade reaction and $A$ is an empirical constant given for monotonic loading as:

$$
A=\left(3-0.8 \frac{z}{D}\right) \geq 0.9
$$

$P_{u}$ is ultimate soil reaction calculated at a given depth as:

$$
P_{u}=\min \left\{\begin{array}{l}
\left(C_{1} z+C_{2} D\right) \gamma^{\prime} z \\
C_{3} D \gamma^{\prime} z
\end{array}\right.
$$

For the Winkler analysis, $C_{1}, C_{2}$, and $C_{3}$ are chosen $3.3,3.7$, and 63 , respectively. Initial modulus $K$ is considered $26.2 \mathrm{MN} / \mathrm{m}^{3}$ according to API suggestion for the sand below water table (note that the Winkler methods correspond to equivalent saturated conditions). There are three main differences between Winkler/API and the test results, including degree of nonlinearity, stiffness of the soil-pile system, and determination of bearing capacity; Winkler/API shows stiffer, more linear response, with a sudden failure corresponding to the ultimate capacity, than the test results do. It can be concluded that the stiffnesses of API p-y curves are overestimated for the studied short monopile in sand and the shape (or equation) of these curves does not reflect the true nonlinear response of such monopiles.

The results are also compared with those of similar experimental studies conducted by Alderlieste et al. (2011) [25] and Klinkvort and Hededal (2014) [23]. It should be noted that these studies have been carried out under various test setup and, therefore, direct and detailed comparison is not possible; because there are many parameters affecting the results including pile diameter, aspect ratio, pile-soil stiffness, load eccentricity, and soil condition (density and compaction). For example, previous studies have concluded that the behaviour of cohesionless soil depends significantly on the density of the material used [29]. However, some general remarks can be given as follows. The comparison indicates similar general nonlinear responses between three experimental results, but various stiffness and ultimate capacities. Very stiff response and remarkably higher lateral capacity of Klinkvort and Hededal (2014) [23] highlights the effect of 1D more penetration depth and $30 \%$ increase in relative density on monopile behaviour. The present test condition has the most similarity to that of Alderlieste et al. (2011) (almost identical $L / D$ s and relative densities); however, ultimate pile capacity was somewhat larger in the results of Alderlieste et al. (2011) [25] because of the smaller load eccentricity, despite identical $L / D$ $(11 / 2.2=5)$ with the current study.

Table 6. Specifications of the present study compared to two similar works. ${ }^{a}$

\begin{tabular}{lccccc}
\hline Test & $\boldsymbol{D}$ & $\boldsymbol{L}$ & $\boldsymbol{e}$ & $\boldsymbol{D r}(\%)$ & Sand type \\
\hline Present study & $2\left(3.2^{\mathrm{b}}\right)$ & $5 \mathrm{D}$ & $7 \mathrm{D}$ & $\sim 60$ & Froozkuh-161 \\
Alderlieste et al. $2011[25]$ & 2.2 & $5 \mathrm{D}$ & $2.18 \mathrm{D}$ & $58-62$ & $d_{50}=0.24 \mathrm{~mm}$ \\
Klinkvort and Hededal 2014 [23] & 3 & $6 \mathrm{D}$ & $10.5 \mathrm{D}$ & 90 & Fontainebleau \\
\hline${ }^{\mathrm{a}} D$ : diameter; $L$ : embedded length; $e$ : load eccentricity; Dr: relative density; & \\
b Equivalent saturated condition.
\end{tabular}




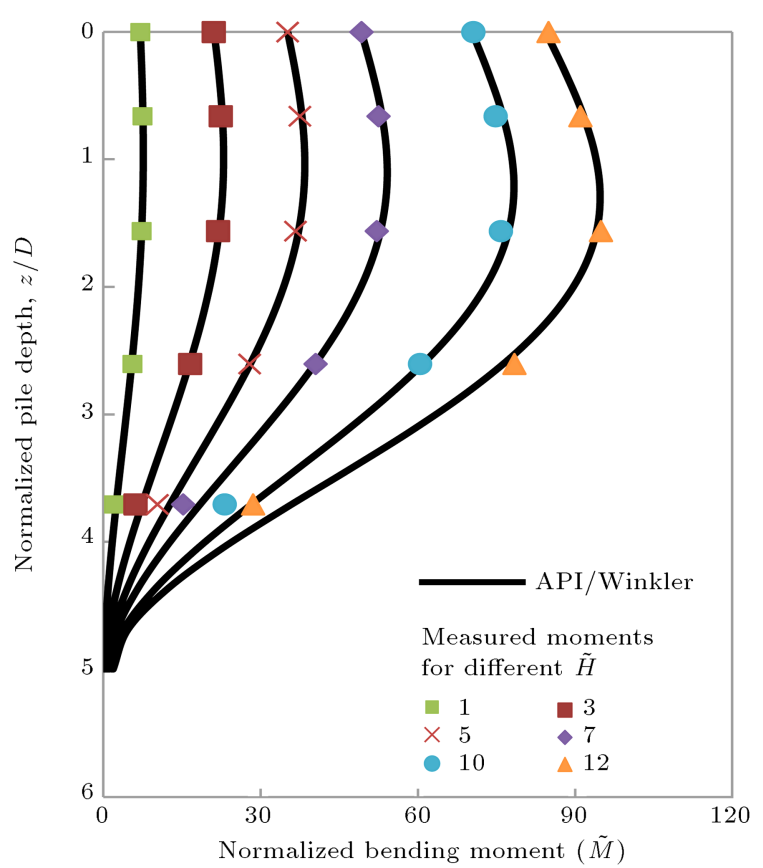

Figure 5. Pile bending-moment diagram for different normalized horizontal loads; experimental results versus $\mathrm{API} /$ springs Winkler model.

The preliminary calibrations for the half-bridge coupled strain gauge arrangement were used to produce a diagram for distribution of bending moments along the pile length. This distribution was also compared with the results of the numerical Winkler model using API recommendations for p-y formulation (Figure 5). The results are presented for some typical normalized horizontal load levels. The general shape of the curves shows the adequacy of the strain gauge stations. With increasing soil depth, bending moments increased until reaching their maximum values and then, decreased gradually. The location of the maximum value became deeper as the load level increased. This implies that by increasing the applied load, upper layers of the soil reached their ultimate resistance. Although the measured moments were in good agreement with the numerical Winkler results, the depths of maximum values in Winkler model were somewhat lower than those in the test measurements.

Experimental p-y curves can be derived from the measured moments. The fifth-order polynomial function introduced by Wilson (1998) [30] was used to fit discrete moments (Eq. (7)). Double differentiating and double integrating of the fitted equations give the soil reaction, $p$, and displacement of the pile $y$, respectively, at any desired depth, $z$. Note that the prototype values in the equivalent saturated sand (i.e. $D=3.2 \mathrm{~m}$ ) were used here.

$$
M(z)=a+b z+c z^{2.5}+d z^{3}+e z^{4}+f z^{5} .
$$

The derived data are illustrated in Figure 6 together

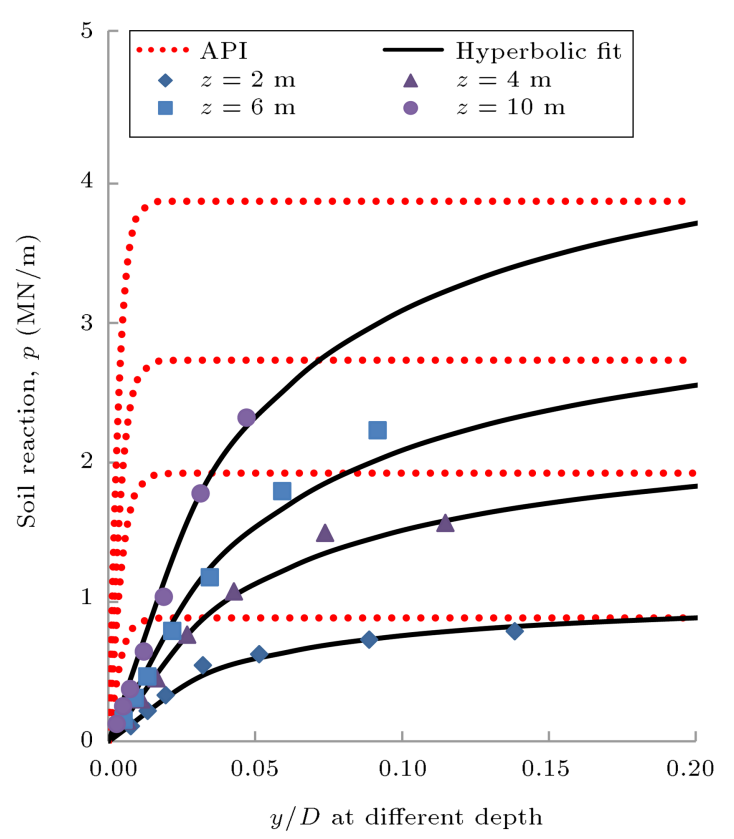

Figure 6. Derived, fitted, and API p-y curves for the monotonic test ( $D=3.2 \mathrm{~m}$, and $D_{r} \sim 60 \%$ ).

with the corresponding API p-y curves for four typical depths. The derived $\mathrm{p}-\mathrm{y}$ points were also fitted to a hyperbolic function firstly proposed by Kondner (1963) [31] and then, identified by Georgiadis et al. (1992) [32] (see Eq. (8)).

$$
p=\frac{y}{\frac{1}{k_{i}}+\frac{y}{p_{u}}},
$$

where $k_{i}$ is the initial stiffness and $p_{u}$ is ultimate soil reaction. As it was not possible to identify $p_{u}$ from the test, an estimation of 1.2 times that proposed by API was assumed for $p_{u}$, which gave the best results for fitting curves. Looking at the graph, the hyperbolic function seems to well fit the test data. API p-y curves obviously failed to predict real soil springs in terms of both formulation and initial stiffness values, as they highly over-predicted the soil stiffness. To quantify this, the calculated values of $k_{i}$ are plotted and compared with those of API for the present sand in saturated condition (Figure 7 ). It can be seen that $k_{i}$ varies almost linearly with depth in agreement with the API suggestion; however, the API estimation for modulus of subgrade reaction is about 8 times larger than that of the present study. Looking at the load-displacement responses (Figure 4) and the corresponding p-y curves (Figure 7), one may conclude that the general loaddisplacement response of the pile almost follows the general shape (or formulation) of the p-y curves.

Normalised pile deflections along depth under the various horizontal loads are provided in Figure 8. As shown, the pile behaves in a rigid manner. As distinguishing limits for rigidity of a pile, the following criteria are often used for sandy soils, which often have 


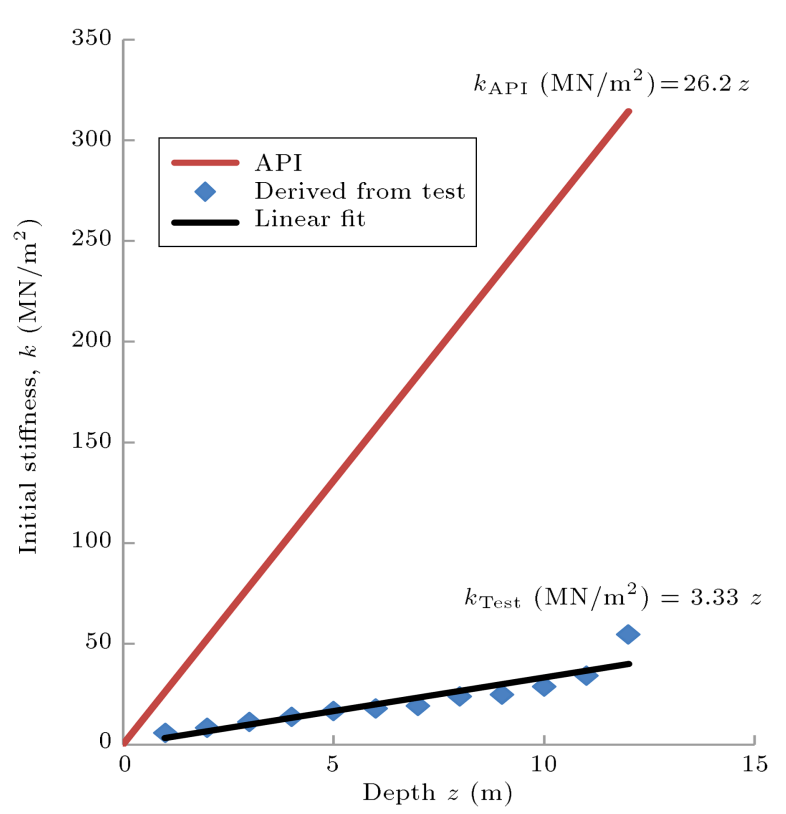

Figure 7. Initial stiffness variation in the monotonic test $\left(D=3.2 \mathrm{~m}\right.$, and $\left.D_{r} \sim 60 \%\right)$.

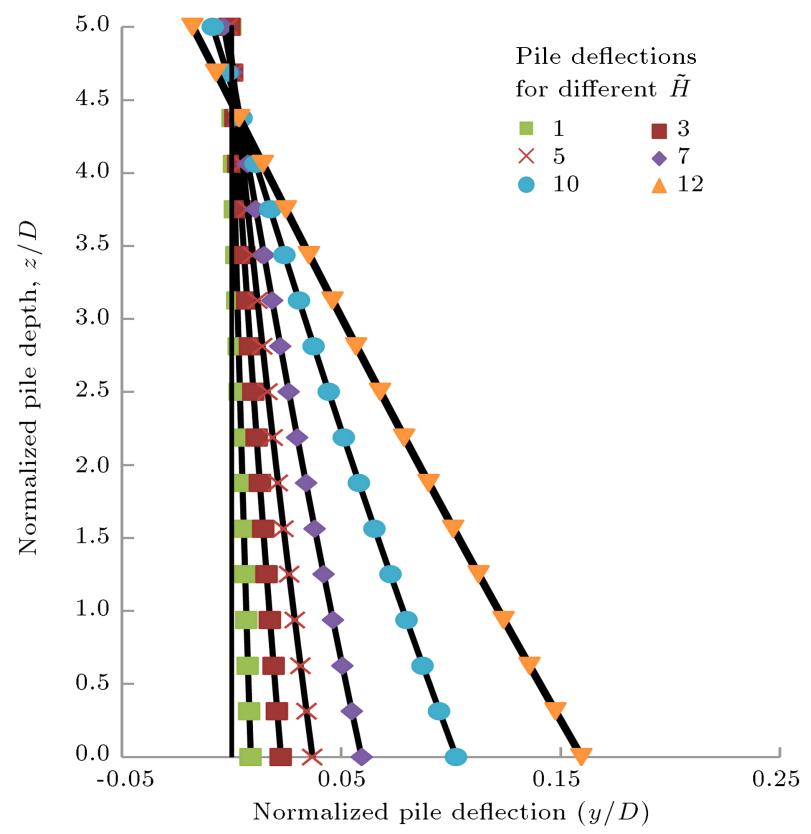

Figure 8. Normalized pile deflections along depth for different normalized load levels.

linearly varying modulus of subgrade reaction with depth $[33,34]$ :

$$
\begin{aligned}
& \frac{L}{T} \leq 2, \quad \text { Rigid piles }, \\
& \frac{L}{T} \geq 4, \quad \text { Slender piles },
\end{aligned}
$$

where $L$ is the pile embedded length and $T$ is the relative stiffness factor introduced by Reese and Matlock
(1956) [3]:

$$
T=\left(\frac{E_{P} I_{P}}{n_{h}}\right)^{\frac{1}{5}} .
$$

$n_{h}$ is coefficient of subgrade reaction modulus. The pile will be considered rigid if $n_{h}$ is:

$$
n_{h} \leq \frac{32 E_{P} I_{P}}{L^{5}} .
$$

For the present case in equivalent saturated condition $(L=16 \mathrm{~m}, D=3.2 \mathrm{~m}, t=8 \mathrm{~cm}$, and $E=207 \mathrm{GPa})$, the pile behaves in a rigid pattern if $n_{h} \leq 6$. The value of $n_{h}$ for the present study is estimated to be 3.33 (Figure 7), which denotes that the pile can be classified within rigid category.

\subsection{Cyclic tests}

Non-dimensional results of the four representative tests were used to investigate the load response and loaddisplacement behaviours of the monopile.

Figure 9 shows the monopile load response versus model time for representative tests $\mathrm{TC} 1, \mathrm{TC} 2, \mathrm{TC} 3$, and TC6. An increase in time (or number of load cycles) caused a change in the minimum and maximum loads. In all tests, the rate of change was rapid during the first few cycles (maximum of 20 cycles for TC1). After about 100 cycles in all tests, the variation in load magnitude became very slow. Different rates of changing in applied loads were observed for different loading patterns. This was due to restructuring of the soil body and sand flowing around the pile under applied cyclic displacements. Under load control condition, this restructuring and sand flowing caused accumulation of irreversible displacement of pile in loading direction [35].

\subsubsection{Load-displacement response and soil deformation}

Figure 10 shows the load-displacement responses of the pile in non-dimensional form. Displacement was measured at the load point. All tests showed nonlinear hysteretic behaviour for the soil-pile system. For tests $\mathrm{TC} 1, \mathrm{TC} 2$, and $\mathrm{TC} 6$ with $y_{\min } / y_{\max }<0$, a softening portion could be observed in the response. This softening portion was remarkable in TC1 where the maximum displacement amplitude was applied. Generally, components of soil-pile interaction affect soil load-displacement response. These components are mainly resistance of the soil against pile moving, gap development (sometimes filling by sand flowing), and drag force (moving the pile in the gap) [36,37]. It seems that the softening is the result of mechanical degradation under cyclic loading [38], which consists in gap development and local plastic deformations in the soil body. In all cases, nonlinearity in terms of elastoplastic response was observed, which should be taken 

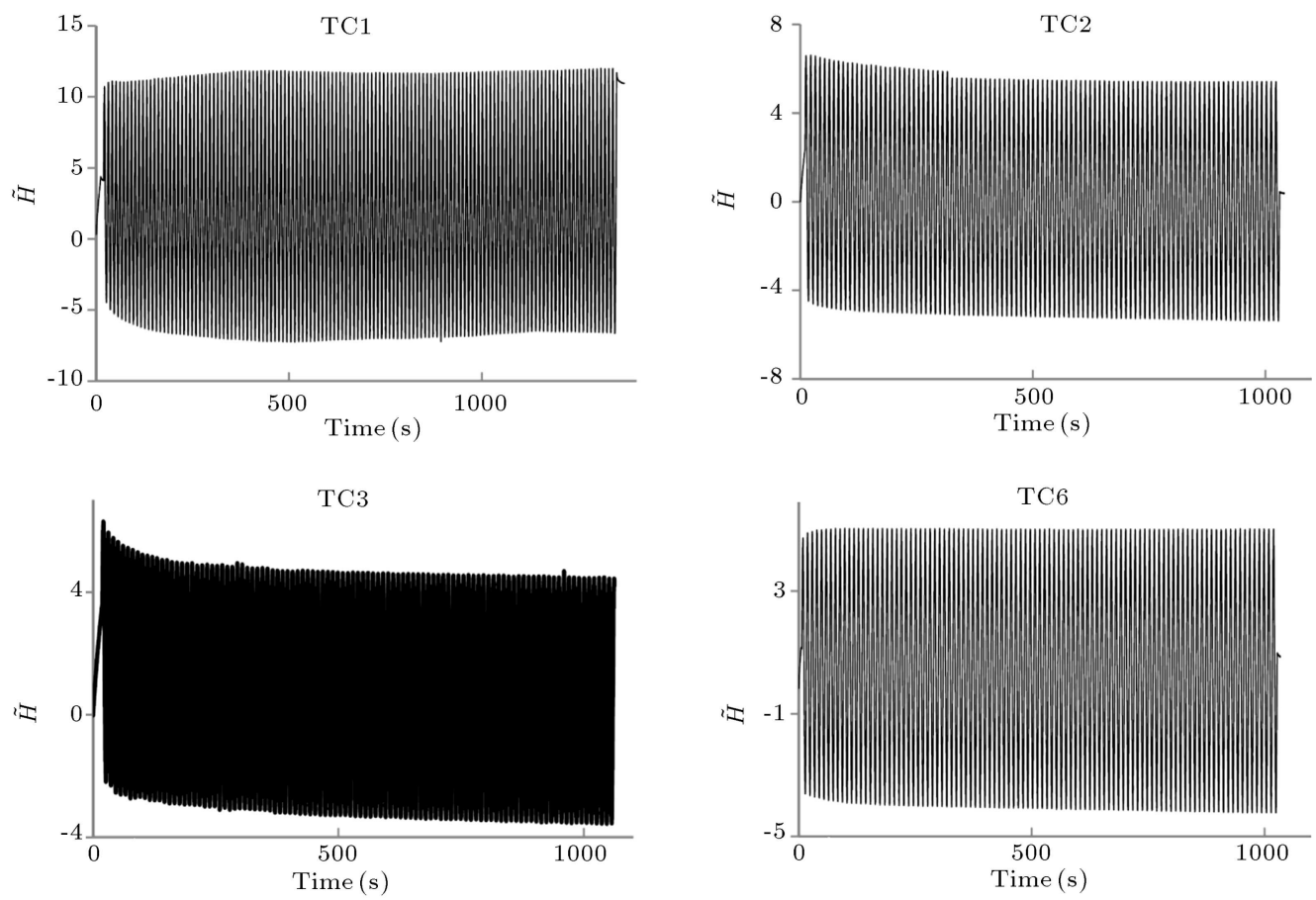

Figure 9. Time history of the resultant applied loading for cyclic tests.
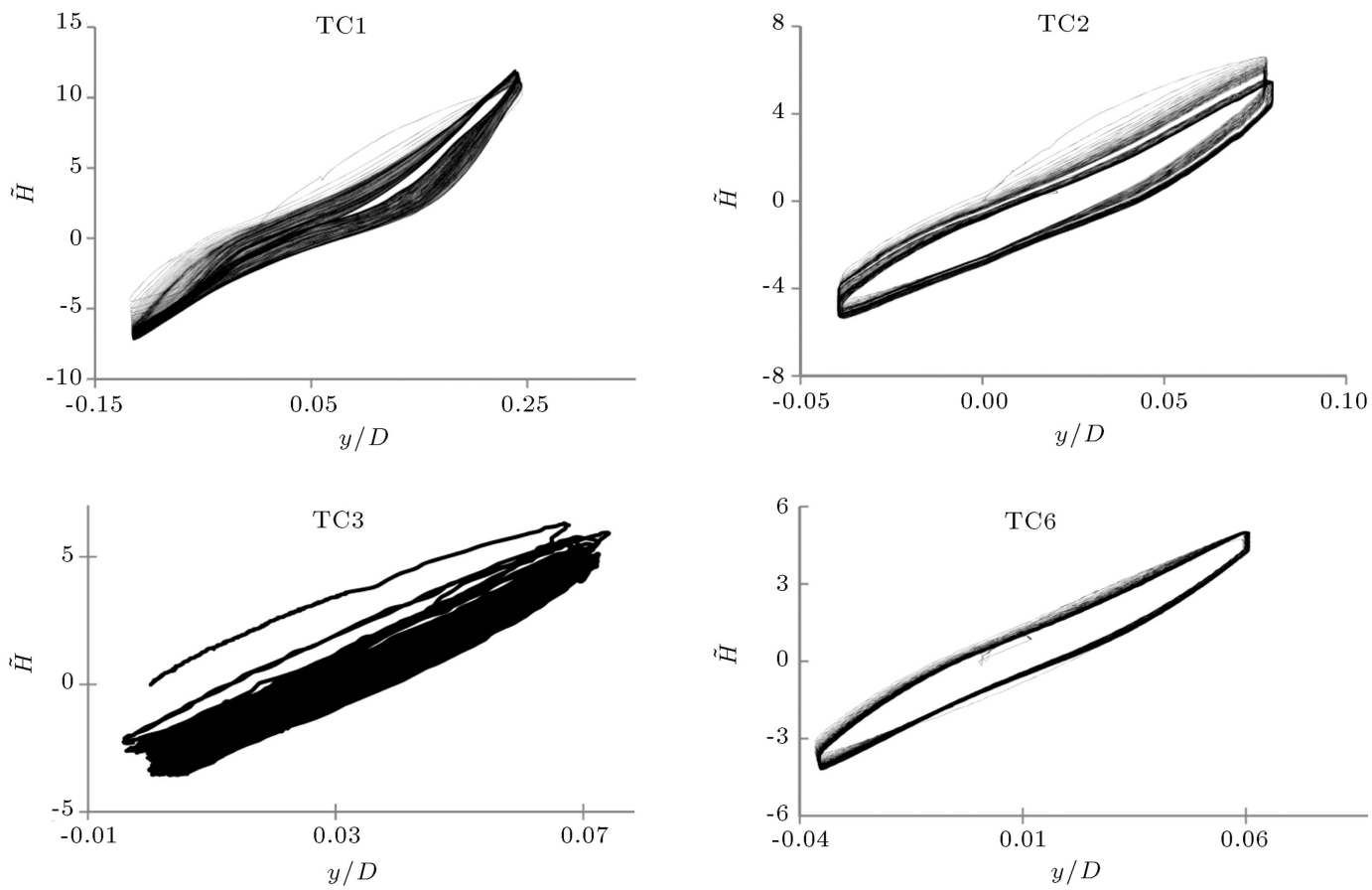

Figure 10. Hysteretic load-displacement curves for cyclic tests.

into consideration in the design stage. From the point of view of dynamics, this nonlinearity would result in changes in the system stiffness and consequently, the natural frequency depending on applied load levels.

Despite overall nonlinearity and elasto-plastic response, loading and unloading curves were close to linear for small applied cyclic amplitudes. This nearly linear loading and unloading region suggests that the stiffness of the soil-pile system remains linear if the load level remains small. This is in agreement with Zaaijer (2006) [39], who showed that linear stiffness matrix models of OWT foundations could be used for dynamic modelling to provide enough accuracy when compared with fully nonlinear soil spring models corresponding to loading conditions that reflected fatigue limit state.

Figure 11 shows soil deformation around the pile 


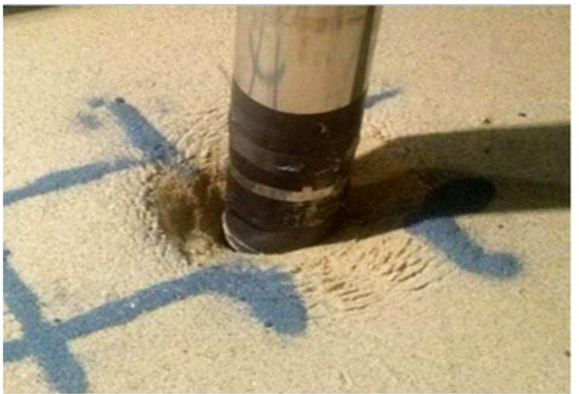

(a)

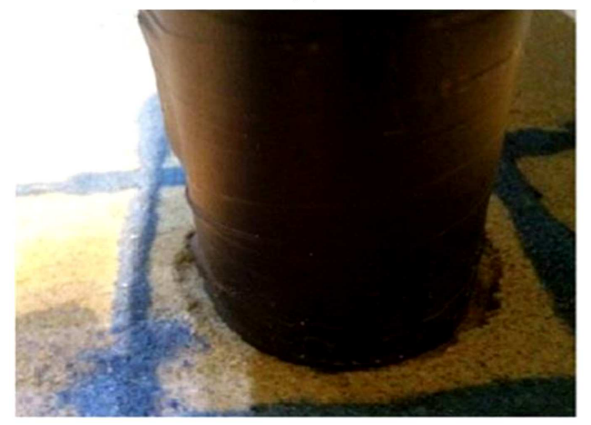

(c)

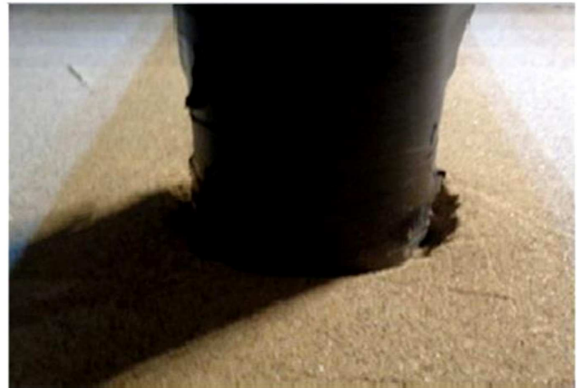

(b)

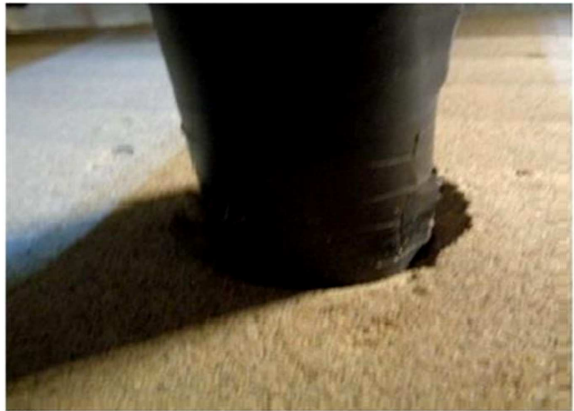

(d)

Figure 11. Soil deformation around pile head after cyclic testing: (a) TC1, (b) TC2, (c) TC3, and (d) TC6.

head. Conical depressions were observed around the pile after all tests because of the dryness of the sand and its low relative density. Similar to softening in hysteretic curves, size of the depression is remarkable for TC1, where displacement amplitude is large compared to other tests. Note that when the circular hole is formed, the embedded portion of the monopile will decrease and affect the load-displacement response of the pile. It should be noted that other phenomena, including change in soil properties (e.g. relative density), local plasticization, gapping, and backfilling the gap, will affect the results. However, as the results of the following sections will demonstrate, degree of influence of each phenomenon strongly depends on loading pattern.

\subsubsection{Cyclic secant stiffness}

Influence of load cycling and pattern was investigated on stiffness behaviour of the monopile-soil system. Figure 12 shows how the secant stiffness was measured in the present displacement-controlled cyclic load tests. The secant stiffness of the system was calculated at the load point, i.e. at $7 D$ above the sand surface. Nondimensional secant stiffness in the $N$ th cycle is defined as:

$$
\tilde{K}_{N}=\frac{\tilde{H}_{\max , N}-\tilde{H}_{\min , N}}{\tilde{y}_{\max }-\tilde{y}_{\min }} .
$$

The calculated non-dimensional secant stiffness was normalized using non-dimensional secant stiffness of the first cycle, i.e. $\tilde{K}_{1}$. The measured data were also fitted to a logarithmic evolution expressed as the

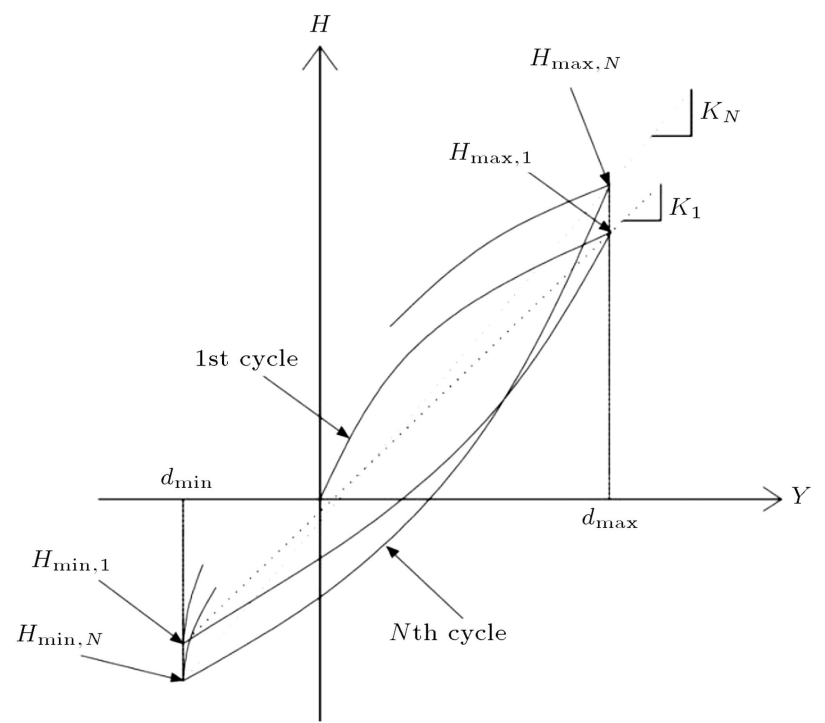

Figure 12. Definition of cyclic secant stiffness.

equation below:

$$
\frac{\tilde{K}_{N}}{\tilde{K}_{1}}=1+a \ln (N),
$$

where the coefficient $a$ is the changing rate. Table 7 summarizes the calculated parameters of logarithmic fit for the cyclic tests. The secant stiffness versus number of cycles for all tests is shown in Figure 13. Fitted curves are depicted with continuous black line and representative measured data are plotted by points. It is shown that most tests well follow the logarithmic trend. However, a degree of scattering is seen in 

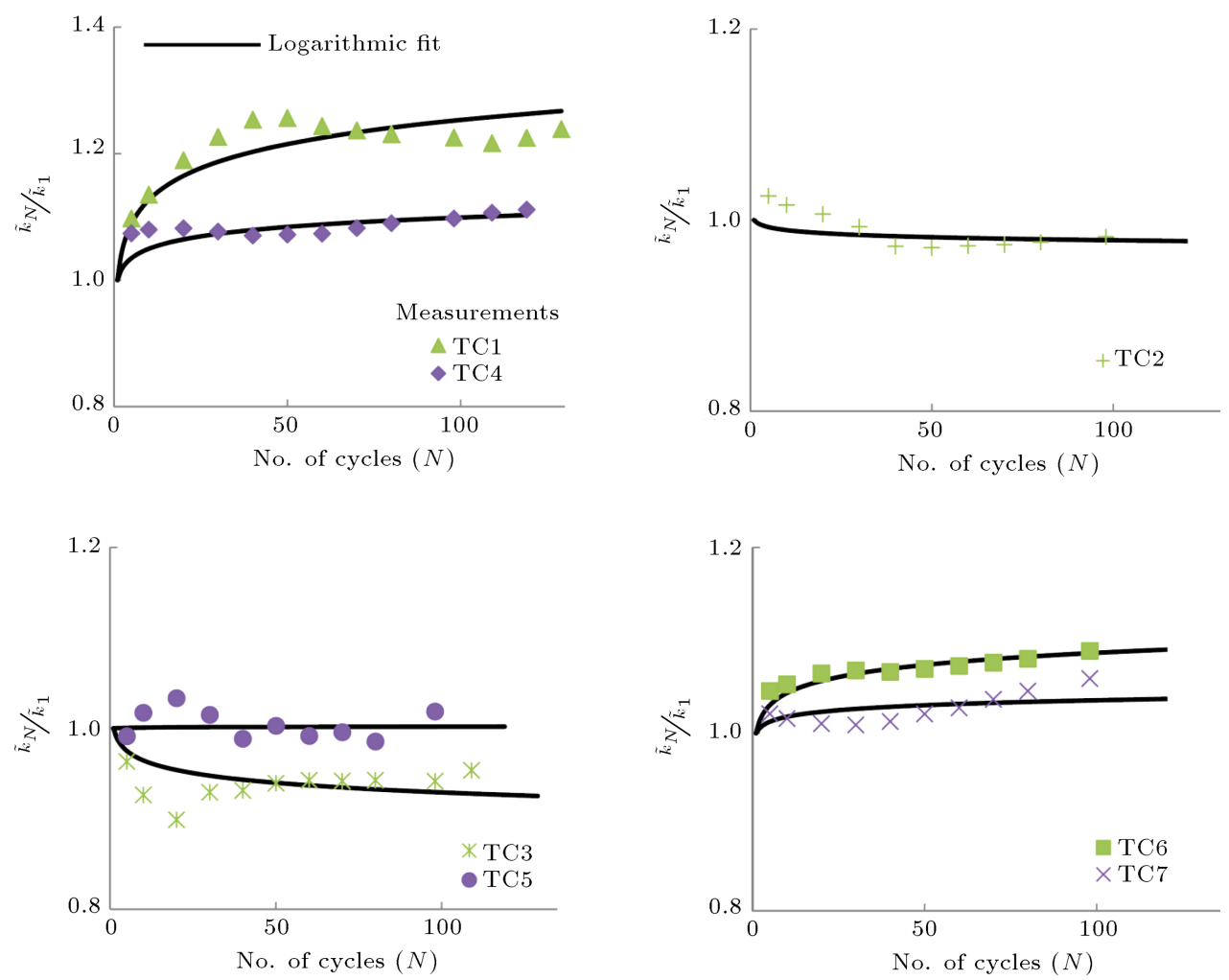

Figure 13. Measurements and logarithmic fit for normalized cyclic secant stiffness.

Table 7. Calculated parameters for logarithmic fit.

\begin{tabular}{cccccc}
\hline Test & $\boldsymbol{y}_{\min } / \boldsymbol{y}_{\max }$ & $\boldsymbol{K}_{\mathbf{1}}$ & $\boldsymbol{a}$ & $\boldsymbol{b}\left(\boldsymbol{y}_{\max }\right)$ & $\boldsymbol{b}\left(\boldsymbol{y}_{\min }\right)$ \\
\hline TC1 & -0.48 & 43 & 0.055 & 0.0084 & 0.0324 \\
TC2 & -0.50 & 92 & -0.0046 & -0.0049 & 0.0041 \\
TC3 & 0 & 105 & -0.0154 & 0.0009 & 0.0056 \\
TC4 & -1 & 67 & 0.0215 & 0.0047 & 0.0029 \\
TC5 & 0.33 & 98 & 0.0004 & -0.0009 & 0.0409 \\
TC6 & -0.67 & 89 & 0.0188 & -0.0069 & -0.0078 \\
TC7 & -0.60 & 77 & 0.0077 & 0.0077 & 0.0133 \\
\hline
\end{tabular}

TC3 and TC5, where $y_{\min } / y_{\max }>0$. Increasing, decreasing, and invariable trends in secant stiffness can be observed in the results. This makes prediction of the long-term behaviour of the monopile-soil system more challenging. Recent studies [1,12] have solved this problem by quantifying the cyclic load content in both direction and magnitude. Although these data may not be enough to achieve a general conclusion, it can be stated that in one-way applied displacements or initial one-way loading condition (i.e. $y_{\min } / y_{\max }>$ $0)$, increase in secant stiffness is unlikely. In twoway applied displacements or initial two-way loading condition (i.e. $y_{\min } / y_{\max }<0$ ), both increasing and decreasing trends are observed in the results.

The greatest increase occurred in test TC1 to which the largest $y_{\max } / y_{\text {ult }}$ was applied. In most tests, changes in cyclic secant stiffness after cycle 50 were very slow and the greatest change was observed in the first 10 cycles.

At this point, it is worth noting that the current design codes such as API [28] and DNV.GL [40] consider the effect of cyclic load only by decreasing the soil ultimate reaction. It is obvious that the results of the present study are in contradiction to the assumption of these methods, i.e. always reducing the pile secant stiffness under cyclic load.

\subsubsection{Cyclic bending moments}

Maximum bending moments of the pile shaft

One key parameter in the structural design of monopiles is maximum bending moment, which is critical to sections such as weld connections that are important to fatigue design. It is important to know how the maximum bending moment will be affected by the cyclic process on the pile. To investigate this, dimensionless moment arm is defined as follows:

$$
\tilde{d}_{N}=\frac{\tilde{M}_{N}}{\tilde{H}_{N}},
$$

It is obvious that $\tilde{d}_{N}$ is always $>\frac{e}{D}=7$. This definition allows eliminating the effect of variation of applied load on the maximum bending moments and therefore, considering only the effect of cycling process on the results. The relative maximum $\tilde{d}_{N}$ for the pile shaft under maximum and minimum applied displacements (maximum $\tilde{d}_{N}$ is measured separately for $y_{\max }$ and 

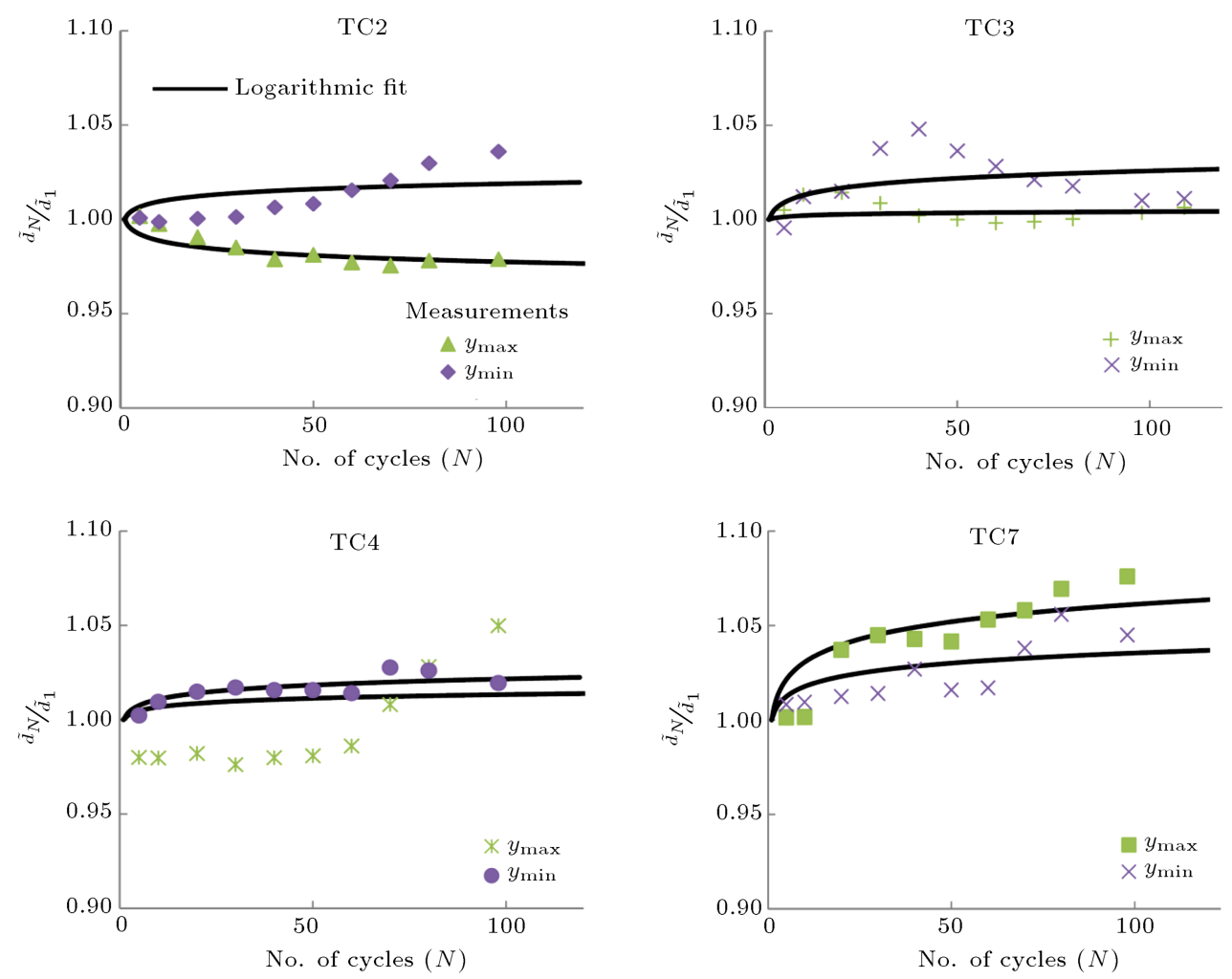

Figure 14. Measurements and logarithmic fit for normalized maximum moment arm of the pile when maximum and minimum displacements are applied.

$\left.y_{\min }\right)$ against the number of cycles is presented for four typical tests. The results are fitted to a logarithmic evolution defined as:

$$
\frac{\tilde{d}_{N}}{\tilde{d}_{1}}=1+b \ln (N) \text {. }
$$

The values of $b$ from curve fitting are presented in Table 7. As the graphs in Figure 14 show, logarithmic variation is present in most cases, but this is not a general finding. Effect of cyclic load on variation of maximum bending moment is observed to be less than $5 \%$ in most tests, except TC7 at $y_{\text {min }}$. Evolution of maximum bending moment was investigated by cyclic load-controlled testing by Rosquoët et al. (2007) [11]. They concluded that the change in maximum bending moment was less than $8 \%$, which is in agreement with the results of the present study. Therefore, it can be concluded that the effect of cyclic load on maximum bending moment will not be of great concern in design practice.

Bending moments distribution along the pile length Normalized moments measured at each of the strain gauges are shown in Figure 15. $M$ is the measured bending moment when the maximum applied load occurs during a load cycle and $M_{0}$ is the corresponding applied bending moment at the pile head. As it is shown, the general shape of the bending profile along the pile length remains relatively unchanged despite changing in the applied cyclic characteristics. However, the location of the maximum bending moment is exchanged between $\frac{z}{D}=0.66$ and $\frac{z}{D}=1.56$ in all tests except TC3.

\section{Conclusion}

A series of centrifuge tests were conducted to investigate the behaviour of stiff monopiles on sand. One test was performed under monotonic condition and seven tests were cyclic. Displacement-controlled cyclic loading was applied to the monopile. In all tests, relative density of the sand was approximately $60 \%$ and the embedded pile length of 5D and load eccentricity of $7 D$ were kept constant during testing. Cyclic tests focus on loading levels of the fatigue limit state. The monotonic test results were compared with those of the numerical Winkler beam on API recommendation springs and two similar laboratory tests. Some conclusion remarks can be summarized as:

- Experimental results gave consistent results, in agreement with the existing literature; however, the Winkler/API springs model predicted a stiffer response than the present centrifugal test did. Also, 

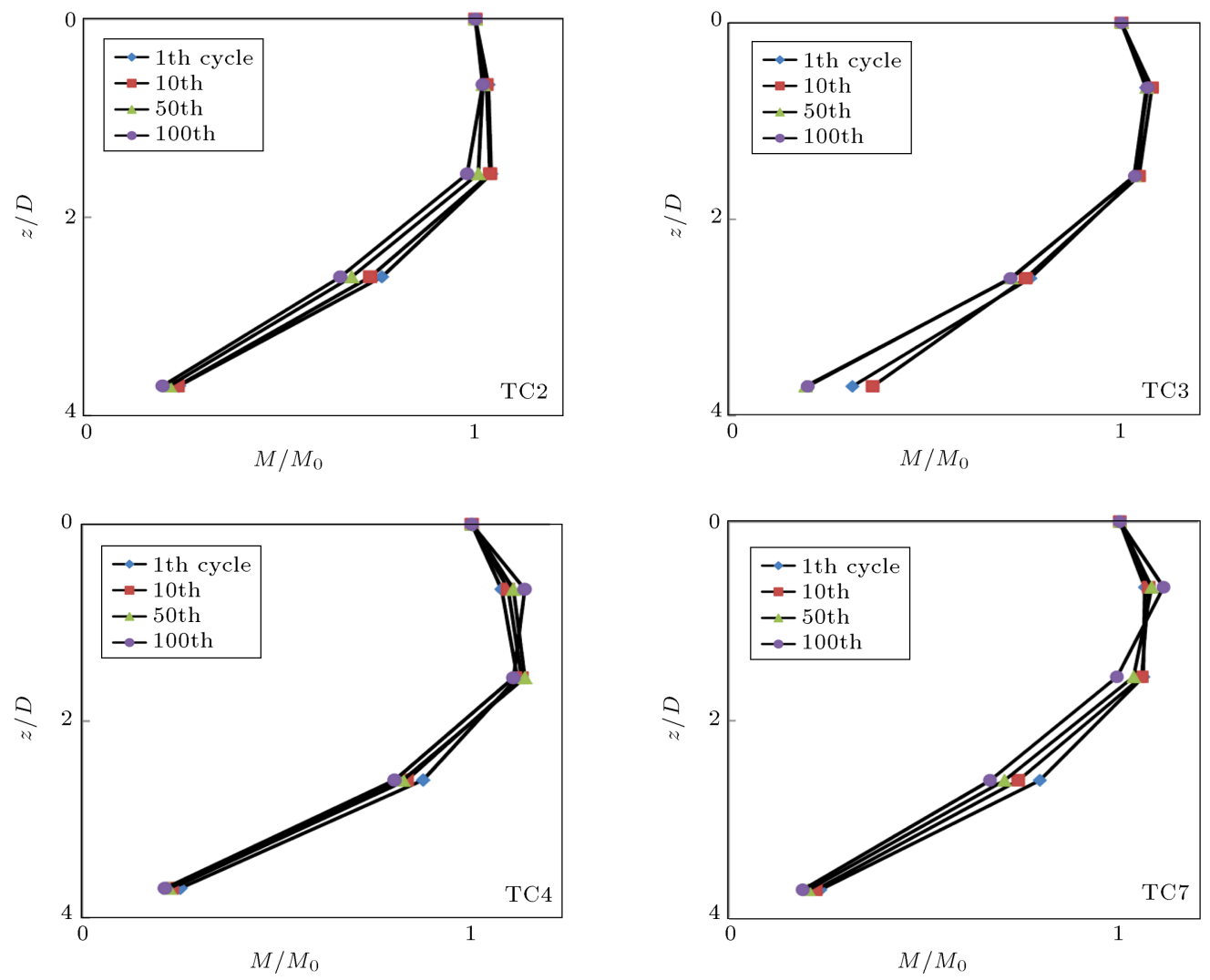

Figure 15. Bending moment distribution along pile when maximum displacement is applied. $M_{0}$ is corresponding moment at the pile head.

nonlinear response was more pronounced in laboratory tests than in API/Winkler;

- The p-y curves derived from bending moment measurements of the monotonic test well fitted a hyperbolic function, while the tangent hyperbolic API p-y curves showed a larger value of initial modulus of subgrade reaction (about 8 times larger than that in this study);

- In some cyclic tests, different rates of change were monitored for applied loads for maximum and minimum applied displacements due to plastic deformations in the soil. The hysteretic behaviour in loaddisplacement curves signified energy dissipation in the soil-pile system;

- Definition of secant stiffness was used to study the stiffness of the soil-pile system. The results showed that the cyclic stiffness of the system strongly depended on the applied cyclic displacement characteristics and degradation; almost no variation and an increase in stiffness occurred;

- Most tests followed a logarithmic trend. The results of tests with one-way applied cyclic displacements $\left(y_{\min } / y_{\max }>0\right)$ showed almost no increase in secant stiffness. In cases with two-way applied cyclic displacements, both decrease and increase in the stiffness were observed. Maximum increase in the secant stiffness occurred for the case of $y_{\min } / y_{\max }<$ 0 with maximum $y_{\max } / y_{u l t}$;

- It was found that the load cycling effect on the pile maximum bending moment was not remarkable. The maximum bending moment of the pile shaft changed to less than $5 \%$ in all cases except one. Also, the moment distribution along the pile was less affected by the cycling process.

\section{Acknowledgements}

This work was carried out at the Physical Modelling and Centrifuge Laboratory of the Department of Soil Mechanics and Foundation Engineering, School of Civil Engineering, University of Tehran. The authors would like to thank all the experts and personnel at the laboratory, especially Mr. Salimi and Mr. Jabbarzade, for their helpful assistance.

\section{References}

1. Leblanc, C., Houlsby, G.T., and Byrne, B.W. "Response of stiff piles in sand to long-term cyclic lateral loading", Géotechnique, 60(2), pp. 79-90 (2010).

2. Achmus, M., Abdel-Rahman, K., and Kuo, Y.S. "Behaviour of large diameter monopiles under cyclic horizontal loading", 12th International Colloquium 
on Structural and Geotechnical Engineering (ICSGE) Cairo, Egypt, GTE039 (2007).

3. Reese, L. and Matlock, H. "Non-dimensional solutions for laterally loaded piles with soil modulus assumed proportional to depth", In Proceedings of the 8th Texas Conference on Soil Mechanics and Foundation Engineering, Austin, TX, pp. 1-23 (1956).

4. McClelland, B. and Focht, J.J.A. "Soil modulus for laterally loaded piles", Journal of the Soil Mechanics and Foundations Division, ASCE, 82(4), pp. 1-22 (1956).

5. Reese, L.C., Cox, W.R., and Koop, F.D. "Analysis of laterally loaded piles in sand", In 6th Annual Offshore Technology Conference: Conference Proceedings, Houston, Tex, pp. 437-483 (1974).

6. O'Neill, M.W. and Murchison, J.M. "An evaluation of p-y relationships in sands", Department of Civil Engineering, University of Houston, TX. Research Rep. No. GT-DF02-83 (1983).

7. Kallehave, D., Byrne, B., Thilsted, C.L., and Mikkelsen K.K. "Optimisation of monopiles for offshore wind turbines", The Philosophical Transactions A of the Royal Society, 373(2035), 20140100 (2015).

8. Li, Z., Haigh, S.K., and Bolton, M.D. "Centrifuge modelling of mono-pile under cyclic lateral loads", In Proceedings of the 7th International Conference on Physical Modelling in Geotechnics (ICPMG 2010), Zurich, Switzerland, pp. 965-970 (2010).

9. Long, J. and Vanneste, G. "Effects of cyclic lateral loads on piles in sand", Journal of Geotechnical and Geoenvironmental Engineering, 120(1), pp. 225-244 (1994).

10. Lin, S.S. and Liao, J.C. "Permanent strains of piles in sand due to cyclic lateral loads", Journal of Geotechnical and Geoenvironmental Engineering, 125(9), pp. 789-802 (1999).

11. Rosquoët, F., Thorel, L., Garnier, J., et al. "Lateral cyclic loading of sand-installed piles", Soils and Foundations, 47(5), pp. 821-832 (2007).

12. Klinkvort, R.T. and Hededal, O. "Lateral response of monopile supporting an offshore wind Turbine", Proceedings of the Institution of Civil Engineers Geotechnical Engineering, 166(2), pp. 147-158 (2013).

13. Lesny, K. and Hinz, P. "Investigation of monopile behaviour under cyclic lateral loading", In Proceeding of the 6th International Conference on Offshore Site Investigation and Geotechnics, London, pp. 383-390 (2007).

14. Achmus, M., Kuo, Y., and Abdel-Rahman, K. "Behaviour of monopile foundations under cyclic lateral load", Computers and Geotechnics, 36(5), pp. 725-735 (2009).
15. Klinkvort, R.T., Leth, C.T., and Hededal, O. "Centrifuge modelling of a laterally cyclic loaded pile", In Proceedings of the 7th International Conference on Physical Modelling in Geotechnics (ICPMG 2010), Zurich, Switzerland, pp. 959-964 (2010).

16. Rudolph, C., Bienen, B., and Grabe, J. "Effect of variation of the loading direction on the displacement accumulation of large-diameter piles under cyclic lateral loading in sand", Canadian Geotechnical Journal, 51(10), pp. 1196-1206 (2014).

17. Taylor, R.N., Geotechnical Centrifuge Technology, Blackie Academic and Professional, Glasgow, Scotland (1995).

18. Klinkvort, R.T., Hededal, O., and Springman, S.M. "Scaling issues in centrifuge modelling of monopiles", International Journal of Physical Modelling in Geotechnics, 13(2), pp. 38-49 (2013). DOI: 10.1680/ijpmg.12.00010

19. Moradi, M. and Ghalandarzadeh, A. "A new geotechnical centrifuge at the University of Tehran, I.R. Iran", Physical Modelling in Geotechnics - Springman, Laue \& Seward (Eds.), Taylor \& Francis Group, London, pp. 251-254 (2010).

20. Farahmand, K., Lashkari, A., and Ghalandarzadeh, A. "Firoozkuh sand: introduction of a benchmark for geomechanical studies", Iran J Sci Technol Trans C (Civil Eng,), 40(C2), pp. 133-148 (2016).

21. Mühlhaus, H.B. and Vardoulakis, I. "The thickness of shear bands in granular materials", Geotechnique, 37(3), pp. 271-283 (1987).

22. Ovesen, N.K. "The scaling law relationships, design parameters in geotechnical engineering", In 7th $E C$ SMFE, Brighton, 4, pp. 319-323 (1979).

23. Klinkvort, R.T. and Hededal, O. "Effect of load eccentricity and stress level on monopile support for offshore wind turbines", Canadian Geotechnical Journal, 51(9), pp. 966-974 (2014).

24. Choo, Y.W. and Kim, D. "Experimental development of the p-y relationship for large-diameter offshore monopiles in sands: centrifuge tests", Journal of Geotechnical and Geoenvironmental Engineering, 142(1), p. 04015058 (2015).

25. Alderlieste, E.A., Dijkstra, J., and Van Tol, A.F. "Experimental investigation into pile diameter effects of laterally loaded monopiles", In Proceedings of the ASME 30th International Conference on Ocean, Offshore and Arctic Engineering (OMAE2011-50068), Rotterdam, The Netherlands, 7, pp. 985-990 (2011).

26. Remaud, D., Physical Modeling of Pile Under Lateral Loads: Interpretation Problem and of Validation, Comptes-rendus du prix jeune chercheur 99, 2 cong. Univ.de genie civil AUGC, Poitiers, France, pp. 185192 (1999).

27. Liu, J., Yuan, B., Mai, V.T., and Dimaano, R. "Optical measurement of sand deformation around a laterally loaded pile", Journal of Testing and Evaluation, ASTM, 39(5), pp. 1-6 (2011). 
28. API (American Petroleum Institute) RP2A-WSD: Recommended Practice for Planning, Designing, and Constructing Fixed Offshore Platforms: Working Stress Design, American Petroleum Institute, Washington DC, USA (2005).

29. Jagodnik, V. and Arbanas, Z. "Testing of laterally loaded piles in natural sandy gravels", International Journal of Physical Modelling in Geotechnics, 15(4), pp. 191-208 (2015).

30. Wilson, D. "Soil-pile-superstructure interaction in liquefying sand and soft clay", Ph.D. Dissertation, University of California, Davis, CA (1998).

31. Kondner, R.L. "Hyperbolic stress-strain response: cohesive soils", Journal of the Soil Mechanics and Foundations Division, ASCE, 89(1), pp. 115-143 (1963).

32. Georgiadis, M., Anagnostopoulos, C., and Saflekou, S. "Centrifugal testing of laterally loaded piles in sand", Canadian Geotechnical Journal, 29(2), pp. 208-216 (1992). DOI: 10.1139/t92-024

33. Poulos, H. and Davis, E., Pile Foundation Analysis and Design, Rainbow- Bridge Book Co., Wiley, New York (1980).

34. Darvishi-Alamouti, S., Bahaari, M.R., and Moradi, M. "Natural frequency of offshore wind turbines on rigid and flexible monopiles in cohesionless soils with linear stiffness distribution", Applied Ocean Research, 67, pp. 91-102 (2017).

35. Qin, H., and Dong Guo, W. "Response of static and cyclic laterally loaded rigid piles in sand", Marine Georesources and Geotechnology, 34(2), pp. 138-153 (2014).

36. Hededal, O. and Klinkvort, R.T. "A new elasto-plastic spring element for cyclic loading of piles using the p-y curve concept", In Numerical Methods in Geotechnical Engineering: NUMGE 2010, Benz and Nordal, Eds., Taylor \& Francis Group, London, pp. 883-888 (2010).

37. Memarpour, M.M., Kimiaei, M., Shayanfar, M., and Khanzadi, M. "Cyclic lateral response of pile foundations in offshore platforms", Computers and Geotechnics, 42, pp. 180-192 (2012).

38. Levy, N.H., Einav, I., and Hull, T. "Cyclic shakedown of piles subjected to two-dimensional lateral loading", International Journal for Numerical and Analytical Methods in Geomechanics, 33, pp. 1339-1361 (2009).

39. Zaaijer, M.B. "Foundation modelling to assess dynamic behaviour of offshore wind turbines", Applied Ocean Research, 28(1), pp. 45-57 (2006).
40. DNV.GL "Support structures for wind turbines", STANDARD DNVGL-ST-0126 (2016).

\section{Biographies}

Saeed Darvishi Alamouti is now a PhD candidate in Marine Structures Engineering at School of Civil Engineering, College of Engineering, University of Tehran, Iran. He received his BSc in Civil Engineering from University of Tehran in 2010. He was granted MSc straight entrance for talented BSc students and received his MSc in Marine Structures Engineering form University of Tehran in 2012. He is accomplishing his $\mathrm{PhD}$ thesis on the subject of offshore monopile wind turbines behavior and has published and submitted journal and conference papers on this subject. His research interest and professional career include analysis and design of coastal and offshore structures, port engineering, dynamic analysis, p-y methods for soil-pile interaction, and offshore wind turbines.

Majid Moradi is an Associate Professor in the School of Civil Engineering, College of Engineering, University of Tehran, Iran. He received his BSc in Civil Engineering in 1989 and MSc in Geotechnical Engineering in 1992 both form University of Tehran, and $\mathrm{PhD}$ in Geotechnical Engineering from University of Manchester, UK, in 1999. He has broad experience in physical modelling in geotechnics, especially employing geotechnical centrifuge facility. Moreover, he has supervised numerous MSc and PhD students with the research subject of the physical and numerical modelling. $\mathrm{He}$ is author and co-author of several research papers in the field of geotechnical engineering, especially physical modelling with centrifuge facility.

Mohammad Reza Bahaari is a Professor in the School of Civil Engineering, College of Engineering, University of Tehran, Iran. He received his BSc in Civil Engineering in 1986 and MSc in Structural Engineering in 1989 both form Sharif University of Technology, Tehran, Iran, and PhD in Solid Mechanics (Structures) from University of Waterloo, Waterloo, Ontario, Canada in 1994. His research area mainly includes offshore structures and sea lines analysis and performance, steel structures, beam to column connections, and multi-planar tubular connections. He also has broad experience in offshore industry, especially South Pars Gas Field development projects. He is author and co-author of several research papers in the field of structural and offshore engineering. 